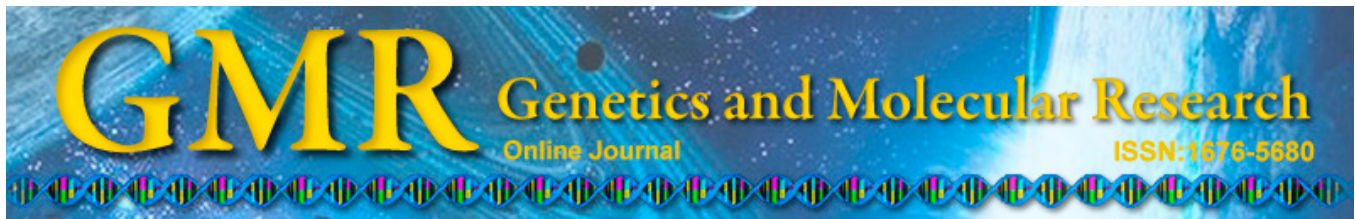

\title{
Use of differential levels of mean observed heterozygosity in microsatellite loci of commercial varieties of sugarcane (Saccharum spp)
}

\author{
R.C. Maranho ${ }^{1}$, R. Augusto ${ }^{2}$, C.A. Mangolin $^{3}$ and M.F.P.S. Machado ${ }^{3}$ \\ ${ }^{1}$ Programa de Pós-Graduação em Agronomia, Universidade Estadual de Maringá, \\ Maringá, PR, Brasil \\ ${ }^{2}$ Programa de Pós-Graduação em Genética e Melhoramento, \\ Universidade Estadual de Maringá, Maringá, PR, Brasil \\ ${ }^{3}$ Departamento de Biotecnologia, Genética e Biologia Celular, \\ Universidade Estadual de Maringá, Maringá, PR, Brasil
}

Corresponding author: M.F.P.S. Machado

E-mail: mfpsmachado@uem.br

Genet. Mol. Res. 13 (4): 10130-10141 (2014)

Received January 7, 2014

Accepted May 28, 2014

Published December 4, 2014

DOI http://dx.doi.org/10.4238/2014.December.4.7

\begin{abstract}
In this study, we measured the genetic diversity within and among a set of 9 commercial sugarcane varieties used for alcohol and sugar production using 17 microsatellite DNA markers. The UGSM148 and UGSM59 primers were monomorphic for all 74 sugarcane samples. The estimated proportion of simple sequence repeated (SSR) polymorphic loci was $88.23 \%$; 17 alleles were detected. The mean gene diversity of all SSR loci was 0.7279 . The
\end{abstract}


highest observed heterozygosity $\left(H_{\mathrm{O}}\right)$ value was found in the RB72454 variety, whereas the lowest $H_{\mathrm{O}}$ value was recorded in the SP813250 variety. The SP813250, RB845210, and RB835054 sugarcane varieties were the most genetically uniform varieties. An extremely high level of population differentiation was detected in the varieties exhibiting similar agronomic characteristics. Analysis of the genetic structure of the 9 sugarcane varieties using SSR markers was especially important to identify SSR loci with high levels of heterozygosity and to identify varieties showing the highest levels of heterozygosity. The monomorphic primers may be used to evaluate the genetic stability of sugarcane during cycles of vegetative multiplication, i.e., propagation via rhizomes.

Key words: Sugarcane; Simple sequence repeat locus; Microsatellite; Genetic diversity; Genetic stability

\section{INTRODUCTION}

Recent use of sugarcane (Saccharum spp) as a source of ethanol and sugar has helped drive the economy of Brazil. In 2010/2011, 624 million tons of sugarcane was produced and subsequently used in the production of 33 million tons of sugar and 27.6 billion liters of ethanol fuel (http://jornalcana.com.br/). The Brazilian sugar and alcohol production system consists of 437 units of production, including 168 alcohol factories, 16 sugar factories, and 253 combined sugar and alcohol factories. Moreover, the bagasse from each ton of sugarcane processed could be used to generate electric energy or to produce additional ethanol. Because bagasse and sugarcane stalk straw have a similar cellulose:lignin:hemicellulose composition, the latter fulfills the same energy-providing purpose (Zanin et al., 2000). Cellobiase and endoglucanase from different sources and different types of pre-treatment are used in the processing of sugarcane bagasse (Martín et al., 2002; Neureiter et al., 2002; Hernández-Salas et al., 2009). Sugarcane bagasse is also used to produce cellulose film (Ruzene et al., 2009) and as an additive material in the production of cement (Sousa, 2009). Additionally, the sugarcane plant is used in the production of biodiesel in the form of sugarcane-derived ethanol, which is a component that is used during the processing of biodiesel in Brazil. Molasses is used for fermentation, and the vinasse is used as a field fertilizer. Sugarcane plants are therefore a symbol of renewable energy for the country (Lee and Bressan, 2006).

The broad utility of sugarcane has stimulated an interest in increasing the production and the development of new varieties that are adapted to different and heterogeneous regions of the country using breeding programs. Sugarcane improvement has been considered an important investment for the development of new varieties. However, Brazilian sugarcane germplasms have low genetic diversity and a narrow genetic base (Barbosa et al., 2000; Almeida et al., 2005). A narrow genetic base is undesirable for sugarcane breeding because a certain level of parental divergence is needed to create productive hybrids. Knowing the genetic diversity of the commercial sugarcane varieties and how they are genetically structured is important for both sugarcane breeding programs and the industrial sector that processes the by-products of sugarcane. High genetic diversity is important for the breeding programs, while genetically uniform varieties are of interest for the industrial sectors. 
The cultivated sugarcane varieties were produced by interspecific hybridization between Saccharum officinarum, S. robustum, S. barberi, and the 2 wild species $S$. spontaneum and $S$. sinense. Because of its diverse origin, sugarcane is thought to have one of the most complex plant genomes, carrying variable chromosome numbers. Modern cultivars generally have between 100 and 130 chromosomes (Grivet and Arruda, 2002). In situ hybridization studies have suggested that modern cultivars inherit approximately $80 \%$ of their chromosomes entirely from $S$. officinarum, approximately $10 \%$ entirely from $S$. spontaneum, and approximately $10 \%$ as the result of recombination among the remaining ancestral species (D'Hont et al., 1996).

The objectives of this study were to measure the genetic diversity within and among commercial sugarcane varieties used for alcohol and sugar production through polymorphic microsatellite DNA markers. The marker systems that are used in studies of sugarcane include microsatellites or simple sequence repeats (SSR) (Cordeiro et al., 2000, 2001; Cordeiro and Henry, 2001; Pan et al., 2003; Pinto et al., 2004). Considerable advances have been made in the area of sugarcane genetics through the use of microsatellite markers. The associations of markers with sugarcane diseases (Wei et al., 2006) and sugar contents (Singh et al., 2008, 2011) have been investigated using sugarcane clones. Microsatellite markers have many desirable genetic attributes, including hypervariability, wide genomic distribution, co-dominant inheritance, reproducibility, multi-allelic nature, and chromosome-specific location. Knowing the observed heterozygosity $\left(H_{\mathrm{O}}\right)$ levels, as well as the differences among the sugarcane varieties, would help us to identify the genotypes that have the highest genetic diversity and measure the genetic divergence between varieties showing similar agronomic characteristics.

\section{MATERIAL AND METHODS}

\section{Sugarcane samples}

A set of 9 sugarcane varieties was chosen to represent part of the germplasm broadly cultivated in the northern region of Parana State and available to the alcohol and sugar factories (Fazenda Junqueira, Alto Alegre district in Colorado, PR, Brazil). The set includes sugarcane varieties from breeding programs at Rede Interuniversitária para o Desenvolvimento do Setor Sucroenergético and Centro de Tecnologia Canavieira. The selections included the following varieties: RB72454, RB845210, RB935744, RB867515, RB835054, RB855453, RB92579, SP813250, and RB036152. The morphological and agronomic characteristics of the varieties are shown in Table 1. The main characteristics of these 9 cultivars that are important for alcohol and sugar production are high productivity and sucrose content, wide adaptability, and resistance to diseases.

\section{Microsatellite selection}

DNA was isolated from young leaves (removed from the cartridge) of 8 plants of each of the RB845210, RB935744, RB867515, RB835054, RB855453, RB92579, SP813250, and RB036152 varieties and 10 plants of the RB72454 variety (74 samples in total) according to the procedure used by Hoisington et al. (1994). The 40 SSR primers previously mapped for sugarcane by the International Sugarcane Microsatellite Consortium (Cordeiro et al., 2000; Singh et al., 2008; Oliveira et al., 2009) were synthesized by Invitrogen Technologies Corporation (USA) and used with 5 DNA samples from each sugarcane variety. After screening 
the 40 SSR primers, a set of 17 SSR primers (Table 2) was selected for further analysis. Polymerase chain reaction (PCR) was performed using a Techne TC-512 thermal cycler. The amplifications were performed by the Touchdown (Td) PCR program (Don et al., 1991) using a primer-specific annealing temperature (TA).

Table 1. Agronomic characteristics and origin of the sugarcane varieties from the Rede Interuniversitária para o Desenvolvimento do Setor Sucroenergético (RB varieties) and Centro de Tecnologia Canavieira (SP variety) breeding programs.

\begin{tabular}{lll}
\hline Variety & Agronomic characteristics & Parents \\
\hline RB72454 & High productivity; wide adaptability & CP53-76 X? \\
RB845210 & High productivity; great sucrose content & RB72454 X SP70-1143 \\
RB935744 & High productivity; excellent health & RB835089 X RB765418 \\
RB867515 & High productivity; high sucrose content & RB72454 X ? \\
RB036152 & Precocity & SP835073 X RB867515 \\
RB835054 & High productivity; wide adaptability & RB72454 X NA56-79 \\
RB855453 & High productivity; high sucrose content & TUC71-7 X ? \\
RB92579 & High productivity; resistant to pests & RB75126 X RB72199 \\
SP813250 & High productivity; high sucrose content & CP70-1547 X SP71-127 \\
\hline
\end{tabular}

Table 2. Simple sequence repeat (SSR) primers previously mapped for sugarcane and the specific annealing temperature (TA) for each primer used in polymerase chain reaction (PCR) of the sugarcane varieties.

\begin{tabular}{|c|c|c|c|c|}
\hline Primer & $\operatorname{SSR}\left(5^{\prime} \rightarrow 3^{\prime}\right)$ & Size (bp) & TA & Forward $(\mathrm{F})$ and reverse $(\mathrm{R})$ primer sequence \\
\hline SMC1237FL & $(\mathrm{CA})_{6}$ & $100-140$ & 58 & $\begin{array}{l}\text { F: TTCACGAACACCCCACCTA } \\
\text { R: GCGCCAGGTAACCTACTGAA }\end{array}$ \\
\hline SMC1047HA & $(\mathrm{GA})_{26}$ & $110-170$ & 62 & $\begin{array}{l}\text { F: TGAGCCTAAGCCAGAAAGAAG } \\
\text { R: GGAACTAATTTCCTACGAGAACAC }\end{array}$ \\
\hline SMC2017FL & $(\mathrm{CTT})_{13}$ & $210-260$ & 62 & $\begin{array}{l}\text { F: CACAAGTGAAGATAATAGTGTCCCT } \\
\text { R: GATCCCAAATCCCTTGATCTC }\end{array}$ \\
\hline SMC16SA & $(\mathrm{CA})_{11}$ & $90-130$ & 58 & $\begin{array}{l}\text { F: GCAACCGCGTCCTCATAC } \\
\text { R: GAGCTTCTGATCGGCCTTC }\end{array}$ \\
\hline SMC226CG & $(\mathrm{CA})_{10}$ & 136 & TD & $\begin{array}{l}\text { F: GAGGCTCAGAAGCTGGCAT } \\
\text { R: ACCCTCTATTTCCGAGTTGGT }\end{array}$ \\
\hline UGSM148 & $(\mathrm{GAA})_{5} \mathrm{GGGCA} . .(\mathrm{GAG})_{5}$ & $42-647$ & TD & $\begin{array}{l}\text { F: GATGACTCCTTGTGGTGG } \\
\text { R: CTTGACGACCCTGCTGCT }\end{array}$ \\
\hline UGSM59 & $(\mathrm{GGC})_{77}$ & $71-500$ & 55 & $\begin{array}{l}\text { F: GTGAACGACTCCATCGCC } \\
\text { R: TTGAAACCACCGTAAATAAGA }\end{array}$ \\
\hline UGSM38 & $(\mathrm{ACG})_{7}$ & $50-1185$ & 55 & $\begin{array}{l}\text { F: CCGAGTGATGATGTGATGT } \\
\text { R: GGGACAACTAATGTAACTGATT }\end{array}$ \\
\hline UGSM117 & $(\mathrm{GCT})_{5} \mathrm{GCCAT} . .(\mathrm{TG})$ & $93-867$ & TD & $\begin{array}{l}\text { F: GAGGAGGTGACGGTGGAG } \\
\text { R: GACGCTACGGTTCATTCA }\end{array}$ \\
\hline SEGMS240 & $(\mathrm{GTT})_{12}$ & $100-900$ & 53 & $\begin{array}{l}\text { F: CAACAAGAAAGAACACAATGAG } \\
\text { R: AATGTGAATAACTAGGTGGTCC }\end{array}$ \\
\hline SEGMS1069 & $(\mathrm{AGA})_{10}$ & $100-600$ & 53 & $\begin{array}{l}\text { F: CGGGAATTCGATTTCATGGGTTC } \\
\text { R: GACTACTCTAAGCATCGTCCTC }\end{array}$ \\
\hline ESTB130 & $(\mathrm{CAA})_{13}$ & 124 & 50 & $\begin{array}{l}\text { F: GCCCAGGTAATTATCCAGACTC } \\
\text { R: GCTGTTGCTCACTGGTTCC }\end{array}$ \\
\hline ESTB41 & $(\mathrm{CGA})_{8}$ & 163 & 63 & $\begin{array}{l}\text { F: CATGGAGAGCTGGGCGACCTG } \\
\text { R: GGCGGCGGCGAGGATGA }\end{array}$ \\
\hline ESTB145 & $(\mathrm{CCT})_{5}$ & 234 & 68 & $\begin{array}{l}\text { F: GGGAAGCAAGCGAGAGCAGCAGAG } \\
\text { R: GAGCGCGAGGCCGTTGTTGAG }\end{array}$ \\
\hline ESTB60 & $(\mathrm{TTG})_{10}$ & 198 & 53 & $\begin{array}{l}\text { F: AGCCGCAATGAATCCAACTG } \\
\text { R: CTCTAGCTCCGACGATGATACCTC }\end{array}$ \\
\hline ESTC66 & $(\mathrm{CCGC})_{3}$ & 152 & 61 & $\begin{array}{l}\text { F: AGTACAGGCTGCTCTCAATCAA } \\
\text { R: TCTGTCATCTGTGTTCGTTCTG }\end{array}$ \\
\hline mSSCIR56 & $(\mathrm{GT})_{24}$ & $125-170$ & 58 & $\begin{array}{l}\text { F: ATTTGACGCTACGATGGTG } \\
\text { R: ATCCGTTTTTCAGCAGAGC }\end{array}$ \\
\hline
\end{tabular}

Cordeiro et al. (2000); Singh et al. (2008); Oliveira et al. (2009). TD = Touchdown (Don et al., 1991). 
For Td-PCR, $20-\mu \mathrm{L}$ volumes containing $25 \mathrm{ng}$ genomic DNA; $10 \mathrm{mM}$ Tris-HCl, $\mathrm{pH}$ $8.8 ; 2.0 \mu \mathrm{L} 10 \mathrm{X}$ reaction buffer $(20 \mathrm{mM}$ Tris- $\mathrm{HCl}, \mathrm{pH} 8.0,0.1 \mathrm{mM}$ ethylenediaminetetraacetic acid (EDTA), $1.0 \mathrm{mM}$ dithiothreitol, and 50\% (v/v) glycerol); $2.5 \mathrm{mM} \mathrm{MgCl}_{2} ; 0.1 \mathrm{mM}$ each dATP, dGTP, dCTP, and dTTP; $0.3 \mu \mathrm{L}$ each primer (F and R primers); and 1 unit Taq polymerase (Invitrogen) were used. The PCR conditions were as follows: initial denaturation at $94^{\circ} \mathrm{C}$ for $1 \mathrm{~min} ; 10$ cycles of $1 \mathrm{~min}$ at $94^{\circ} \mathrm{C}, 1 \mathrm{~min}$ with an initial temperature of $65^{\circ} \mathrm{C}$ and a reduction of $1^{\circ} \mathrm{C}$ per cycle, and $2 \mathrm{~min}$ at $72^{\circ} \mathrm{C}$; and 20 cycles of $1 \mathrm{~min}$ at $94^{\circ} \mathrm{C}, 1 \mathrm{~min}$ at $55^{\circ} \mathrm{C}$, and $2 \mathrm{~min}$ at $72^{\circ} \mathrm{C}$. The final extension was $5 \mathrm{~min}$ at $72^{\circ} \mathrm{C}$. The PCR using specific temperatures for the primer annealing was $94^{\circ} \mathrm{C}$ for 5 min followed by 30 cycles of $94^{\circ} \mathrm{C}$ for $1 \mathrm{~min}$ and the TA of each primer for $1 \mathrm{~min}$, and later cycles with $72^{\circ} \mathrm{C}$ for $1 \mathrm{~min}$. The final extension was $15 \mathrm{~min}$ at $72^{\circ} \mathrm{C}$.

After amplification, a total of $20 \mu \mathrm{L}$ of each sample (74 total samples) was separated by electrophoresis on a $4 \%$ agarose gel (50\% agarose and 50\% agarose Metaphor, CAMBREX) containing 0.5X TBE buffer ( $44.5 \mathrm{mM}$ Tris, $44.5 \mathrm{mM}$ boric acid, and $1 \mathrm{mM}$ EDTA). All 72 samples amplified by a single SSR primer were run on the same gel at $60 \mathrm{~V}$ for $4 \mathrm{~h}$. A 1-kb ladder (Invitrogen) was used as the weight molecular marker. Gels were stained using $0.5 \mu \mathrm{g} /$ $\mathrm{mL}$ ethidium bromide, and the image was captured using Molecular Image Loccus L-PIX-HE using the Picasa 3 program.

\section{Microsatellite analysis}

The allele numbers per locus were determined based on their relative positions in the gel. The presence of a particular allele or peak was given a score of 1, and its absence was given a score of 0 . The binary matrix was analyzed using the Popgene 1.32 software (Yeh et al., 1999) and NTSYSpc version 2.1 (Rohlf, 2000). Cluster analysis among the Saccharum varieties was based on Jaccard's similarity coefficient using the unweighted pair group method analysis (UPGMA). Genetic variability within each variety of sugarcane was represented by mean $H_{\mathrm{O}}$. Heterozygous phenotypes for the different alleles were scored within each variety.

\section{RESULTS}

Two primers (UGSM148 and UGSM59) were monomorphic for all 74 sugarcane samples analyzed, and the other 15 primers amplified 2 or more products (polymorphic loci). The estimated proportion of polymorphic SSR loci (\%P) in the 9 varieties was $88.23 \%$. Seventy alleles, or an average of 4.12 alleles per locus, were detected in the leaves of the 9 varieties of sugarcane plants (Table 3). PCR using primer-specific TA was an efficient strategy because the well-defined extra bands exhibited similar intensities on the gel.

The highest number of alleles (8.0) was detected at the mSsir56 locus, and the highest gene diversity $(H o=1.000)$ was detected at the Smc226CG, Smc1237FL, Smc1047HA, $m S s i r 56$, and EstB60 loci; the lowest effective number of alleles (1.61) and the lowest gene diversity $\left(H_{\mathrm{O}}=0.2838\right)$ were detected at the Ugsm38, Ugsm117, and EstB145 loci (Table 3). The mean gene diversity of all SSR loci was 0.7279 . The larger effective number of alleles per locus and the higher gene diversity $\left(H_{\mathrm{O}}>0.50\right)$ detected in 11 SSR loci (Segms1069, Smc226CG, EstB130, Smc1237FL, Smc165A, EstB41, Smc1047HA, Smc2017FL, EstC66, $m S s i r 56$, and EstB60) suggest that $73.3 \%$ of the 15 polymorphic SSR loci are adequate and sufficient to determine differences among the 9 sugarcane varieties. 
Table 3. Number of alleles $\left(N_{\mathrm{A}}\right)$ and number of effective alleles $\left(N_{\mathrm{E}}\right)$ per polymorphic SSR locus and mean observed heterozygosity $\left(H_{\mathrm{O}}\right)$ in the 9 sugarcane varieties.

\begin{tabular}{lllcc}
\hline Locus & $\mathrm{N}$ & $N_{\mathrm{A}}$ & $N_{\mathrm{E}}$ & $H_{\mathrm{O}}$ \\
\hline Ugsm38 & 74 & 3.0 & 2.7552 & 0.2838 \\
Segms240 & 74 & 2.0 & 1.6172 & 0.4865 \\
Segms1069 & 74 & 3.0 & 2.9104 & 0.7973 \\
Smc226CG & 74 & 6.0 & 2.9221 & 1.0000 \\
EstB130 & 74 & 5.0 & 3.4473 & 0.9865 \\
Smc1237FL & 74 & 6.0 & 3.9283 & 1.0000 \\
Smc16SA & 74 & 5.0 & 2.9883 & 0.5676 \\
Ugsm117 & 74 & 3.0 & 2.5715 & 0.6388 \\
EstB41 & 74 & 5.0 & 2.9640 & 0.2838 \\
EstB145 & 74 & 2.0 & 1.7951 & 1.0000 \\
Smc1047HA & 74 & 7.0 & 4.7411 & 0.8919 \\
Smc2017FL & 74 & 4.0 & 3.1336 & 0.6892 \\
EstC66 & 74 & 3.0 & 2.5679 & 1.0000 \\
mSsir56 & 74 & 8.0 & 3.0212 & 1.0000 \\
EstB60 & 74 & 6.0 & 2.5904 & 0.7279 \\
Mean & & 4.12 & 2.9302 & \\
\hline
\end{tabular}

Table 4 shows the proportion of alleles per polymorphic locus and mean $H_{\mathrm{O}}$ in the 9 sugarcane varieties. The number of alleles was highest in the RB72454 sugarcane variety (3.12) and lowest in the RB855453 sugarcane variety (2.29). The RB72454 and RB935744 varieties showed the highest number of polymorphic SSR loci (100\%), while the RB835054 variety showed the lowest number of polymorphic SSR loci $(75 \%)$. The highest $H_{\mathrm{O}}$ value (0.8330) was found in the RB72454 variety, whereas the lowest $H_{\mathrm{O}}$ value $(0.5750)$ was recorded in the SP813250 sugarcane variety. The RB845210 and RB835054 sugarcane varieties also showed lower $H_{\mathrm{O}}$ values ( 0.6500 and 0.6580 , respectively) than the $H_{\mathrm{O}}$ values observed in the RB72454, RB935744, RB867515, RB855453, RB92579, and RB036152 varieties. The SP813250, RB845210, and RB825054 sugarcane varieties were the most genetically uniform varieties.

Table 4. Number of alleles per polymorphic SSR locus $\left(N_{\mathrm{A}}\right)$, number of effective alleles $\left(N_{\mathrm{E}}\right)$, mean observed homozygosity $\left(\operatorname{Hom}_{\mathrm{O}}\right)$, mean observed heterozygosity $\left(H_{\mathrm{O}}\right)$, and proportion of polymorphic loci $(\% \mathrm{P})$ in the plants of the 9 sugarcane varieties.

\begin{tabular}{llllrr}
\hline Variety & $N_{\mathrm{A}}$ & $N_{\mathrm{E}}$ & Hom $_{\mathrm{O}}$ & $H_{\mathrm{O}}$ & $(\% \mathrm{P})$ \\
\hline SP813250 & 2.823 & 1.744 & 0.4250 & 0.5750 & 87.50 \\
RB845210 & 2.823 & 1.897 & 0.3500 & 0.6500 & 8.7420 \\
RB935744 & 2.94 & 2.05 & 0.2580 & 0.7920 & 100.00 \\
RB867515 & 2.47 & 2.01 & 0.2080 & 0.7330 & 93.75 \\
RB036152 & 2.35 & 1.92 & 0.2670 & 0.6580 & 81.25 \\
RB835054 & 2.59 & 1.76 & 0.3420 & 0.7330 & 8.00 \\
RB855453 & 2.29 & 1.83 & 0.2670 & 0.8080 & 93.50 \\
RB92579 & 2.59 & 2.03 & 0.1920 & 0.8330 & 100.00 \\
RB72454 & 3.12 & 2.31 & 0.2720 & 0.7280 & 100.00 \\
Total & 4.12 & 2.93 & & &
\end{tabular}

An extremely high level of population differentiation $\left(G_{\mathrm{ST}}\right)$ was detected in samples from all 9 sugarcane varieties $\left(G_{\mathrm{ST}}=0.7034\right)$, with the $G_{\mathrm{ST}}$ for each locus ranging from 0.0578 (Smc1237FL) to 1.0000 (Smc165-1, Smc1047HA, mSscir56-2, and mSscir56-4). The $G_{\mathrm{ST}}$ value indicated that $70.34 \%$ of the total variance in allele frequencies at the SSR loci was due to genetic differences among the 9 sugarcane varieties. 
The dendrogram obtained from UPGMA cluster analysis of Nei's unbiased genetic distance (Nei, 1973) (Figure 1) revealed the formation of 4 main groups: one group comprising plants from the SP813250 and RB036152 varieties; the second group comprising plants from the RB845210, RB855453, and RB867515 varieties; the third group comprising plants from the RB935744 and RB835054 varieties; and the fourth group comprising the most similar (I = 0.8631) RB92579 and RB72454 sugarcane varieties.

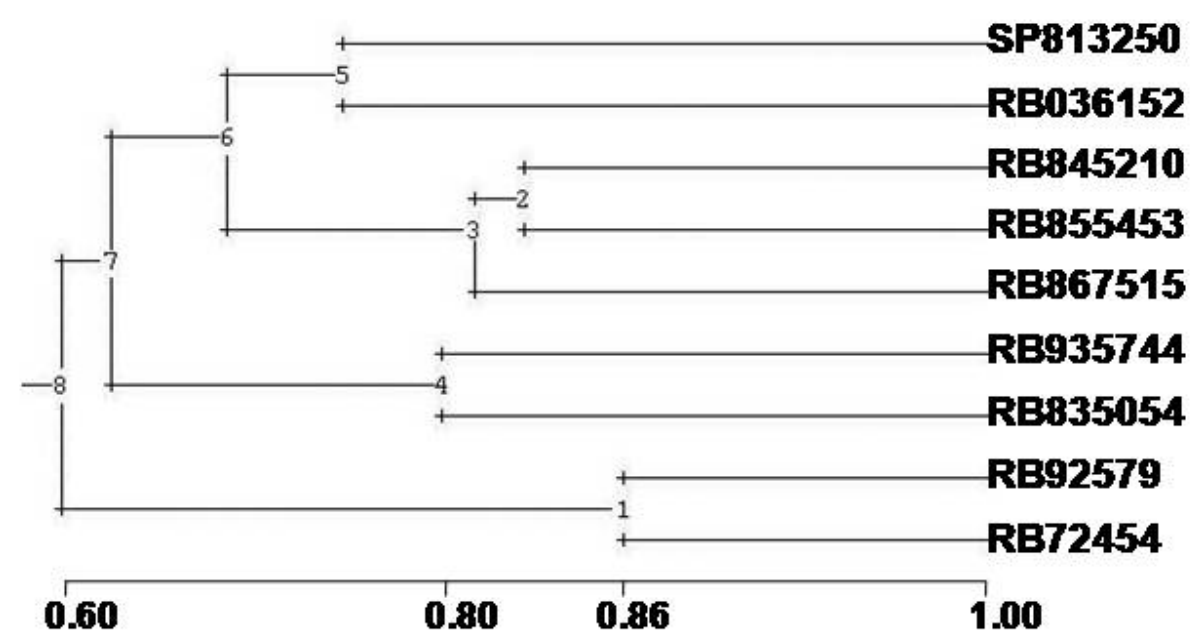

Figure 1. Grouping by the unweighted pair group method analysis (UPGMA) based on genetic similarity measures from simple sequence repeat (SSR) loci between the 9 varieties (SP813250, RB036152, RB845210, RB855453, RB867515, RB935744, RB835054, RB92579, and RB72454) of sugarcane.

Groups 2 and 4 had the highest level of genetic similarity compared to plants from the first and third group. Nei's identity values varied between 0.6142 (in the RB92579 and RB935744 sugarcane varieties) and 0.8631 (in the RB92579 and RB72454 sugarcane varieties) (Table 5). The UPGMA dendrogram based on Jaccard's similarity coefficient (Figure 2 ) represents the genetic variability within each variety of sugarcane. The dendrogram in Figure 2 shows a broad genetic basis $(0.45-1.00)$ for all of the samples analyzed using the 17 SSR loci.

Table 5. Similarity matrix obtained from SSR loci among the 9 varieties (SP813250, RB845210, RB935744, RB867515, RB036152, RB835054, RB855453, RB92579, and RB72454) of sugarcane.

\begin{tabular}{lccccccccc}
\hline Variety & SP813250 & RB845210 & RB935744 & RB867515 & RB036152 & RB835054 & RB855453 & RB92579 & RB72454 \\
\hline SP813250 & $* * * *$ & 0.8069 & 0.7030 & 0.7311 & 0.7717 & 0.6979 & 0.7649 & 0.6869 & 0.6654 \\
RB845210 & 0.2146 & $* * * *$ & 0.7586 & 0.8160 & 0.6915 & 0.6169 & 0.8288 & 0.7283 & 0.7939 \\
RB935744 & 0.3524 & 0.2762 & $* * * *$ & 0.7539 & 0.7163 & 0.8049 & 0.7961 & 0.6142 & 0.7330 \\
RB867515 & 0.3132 & 0.2034 & 0.2825 & $* * * *$ & 0.7213 & 0.6522 & 0.8063 & 0.6703 & 0.7488 \\
RB036152 & 0.2592 & 0.3689 & 0.3336 & 0.3268 & $* * *$ & 0.6844 & 0.7182 & 0.6500 & 0.7183 \\
RB835054 & 0.3596 & 0.4782 & 0.2171 & 0.4273 & 0.3791 & $* * * *$ & 0.7039 & 0.6219 & 0.6797 \\
RB855453 & 0.2680 & 0.1878 & 0.2281 & 0.2153 & 0.3310 & 0.3511 & $* * * *$ & 0.6638 & 0.7514 \\
RB92579 & 0.3756 & 0.3171 & 0.4874 & 0.4000 & 0.4307 & 0.4749 & 0.4098 & $* * * *$ & 0.8631 \\
RB72454 & 0.4074 & 0.2308 & 0.3106 & 0.2892 & 0.3309 & 0.3861 & 0.2859 & 0.1472 & $* * * *$ \\
\hline
\end{tabular}




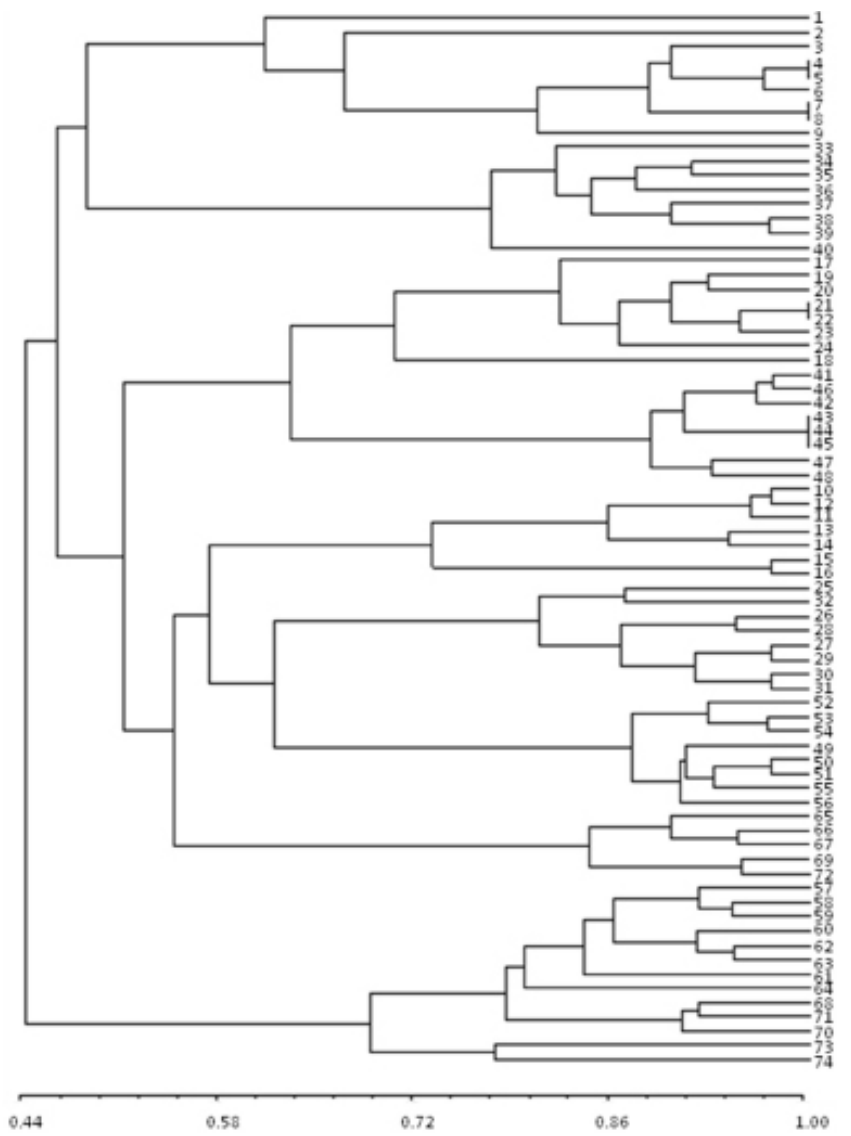

Figure 2. Grouping by the UPGMA based on genetic similarity measures from SSR loci between the 74 plants of the 9 varieties (SP813250, RB036152, RB845210, RB855453, RB867515, RB935744, RB835054, RB92579, and RB72454) of sugarcane.

\section{DISCUSSION}

The adjusted TA for the primers SMC1237FL, SMC1047HA, SMC2017FL, SMC16SA, UGSM59, UGSM38, SEGMS240, SEGMS1069, ESTB130, ESTB41, ESTB145, ESTB60, ESTC66, and mSSCIR56 (Table 2) showed well-defined amplified DNA segments; the faint bands were removed from the gel, and only the segments with similar intensity were counted to avoid overestimating the number of alleles. The number of alleles detected in our study ranged from 2 to 8 per locus, which was similar to what has been reported for other RB sugarcane varieties (Silva et al., 2012) using different SSR primers. The mean number of alleles estimated in our study (4.12 alleles/locus) was also approximately consistent with the mean number of alleles reported in other RB sugarcane varieties (3.2 alleles/locus) (Duarte-Filho et al., 2010), indicating the great potential and high reproducibility of these microsatellite loci to investigate genetic divergence in the sugarcane germplasm. Using a higher number of SSR primers, other breeding programs have reported a correspondingly higher number of alleles at SSR loci (Singh et al., 2008, 2011; Oliveira et al., 2009; Liu et al., 2011). 
The genetic diversity within sugarcane varieties estimated from the mean $H_{\mathrm{O}}$ has not been analyzed in other studies with different sugarcane varieties. The analysis of SSR loci in sugarcane has principally been scored based on the genetic distances, where the estimation of the effective number of alleles and the $H_{\mathrm{O}}$ were not calculated (Singh et al., 2008, 2011; Oliveira et al., 2009; Duarte-Filho et al., 2010; Liu et al., 2011; Silva et al., 2012). In our study, the highest heterozygosity detected at SSR loci, e.g., in the RB72454 variety, is potentially meaningful because high heterozygosity would indicate that the plant population likely has a substantial amount of adaptive genetic variation to escape the effects of a control agent that limits the development and maintenance of the plants (Allendorf and Luikart, 2007), in contrast to plant populations showing a lower level of heterozygosity. RB72454 $\left(H_{\mathrm{O}}=0.8330\right)$ and $\mathrm{RB} 867515\left(H_{\mathrm{O}}=0.7920\right)$ are the 2 varieties widely cultivated in Brazil. It is possible that the high rate of polymorphism that is found in these varieties is the factor that favours the establishment of crops, making them less susceptible to problems such as disease and climate variability; therefore, the wide adaptability of these varieties justifies their use in various regions of the country. The RB72454 variety has also been widely used as a parent of other varieties (Table 1) to obtain sugarcane cultivars that develop in the different types of soil and climate that are present in Brazil.

In our study, the RB835054 variety showed the lowest number of polymorphic loci (75\%), and the SP813250 genotype had the lowest mean $H_{\mathrm{O}}$ value $(0.5700)$ and the lowest number of alleles $\left(N_{\mathrm{A}}=1.74\right)$. Low heterozygosity or high genetic uniformity is considered an important characteristic by industrial sectors when it is associated with morphological and agronomic traits of interest. The genetic uniformity should ensure repeatability in extraction processes, which is an economically important factor for the industrial sector in processing the by-products of sugarcane.

The genetic diversity that was estimated from the dissimilarity matrix among the 9 sugarcane varieties was lower than the genetic diversity that was detected in 30 accessions of other sugarcane varieties using 18 primers. While the genetic similarity among the 9 sugarcane varieties ranged from 0.6242 (RB92579 and RB935744) to 0.8631 (RB92579 and RB72457), the genetic similarity that was estimated in 30 accessions of other RB varieties ranged from 0.56 (RB928054 and RB813904) to 0.95 (RB93509 and RB931011) (Duarte-Filho et al., 2010). The Nei identity values obtained for the 9 sugarcane varieties showed a small genetic basis, which was in contrast to the larger genetic basis reported for other sugarcane accessions. However, a broad genetic basis ( 0.45 to 1.00$)$ was observed when individual plants of the 9 varieties were compared (Figure 2). A comparison of individual plants showed the genetic variability within each variety of sugarcane. A similarity of $100 \%$ for the 17 SSR loci (indicating a clone) was detected only in the SP813250, RB935744, and RB835054 varieties. High and low levels of genetic diversity within other SP and RB varieties have also been reported using random amplification of polymorphic DNA (Silva et al., 2008).

The $G_{\mathrm{sT}}$ among sugarcane varieties has not been described in other studies. In this study, the high differentiation among the 9 varieties $\left(G_{\mathrm{ST}}=0.7034\right)$ suggests the formation of divergent groups. As one of Nei's (1973) genetic diversity statistics, $G_{\mathrm{ST}}$ is defined as the proportion of genetic diversity that resides among populations. It is equivalent to Wright's (Wright, 1951) $F_{\mathrm{ST}}$ when there are only 2 alleles at a locus, and, in the case of multiple alleles, $G_{\mathrm{ST}}$ is equivalent to the weighted average of $F_{\mathrm{ST}}$ values for all alleles (Nei, 1973). According to Nei (1973), $G_{\mathrm{ST}}$ values higher than 0.25 indicate a very high interpopulational divergence level. Understanding the genetic relationship between individual plants from different groups 
may help breeders to select parents when crossing chosen base populations for selection and to maximize heterosis. For example, the RB92579 and RB935744 varieties can be considered as the most genetically divergent varieties for the 17 SSR loci analyzed in our study. The highest $G_{\mathrm{ST}}$ was evident at the Smc16SA, Smc1047HA, and $m S s c i r 56$ loci $\left(G_{\mathrm{ST}}=1.0000\right)$; therefore, the SMC16SA, SMC1047HA, and MSSCIR56 primers are the most adequate primers to characterize the different sugarcane varieties based on the resulting allele frequencies.

Differential levels of genetic variation at SSR loci indicate that particular loci have been the target of artificial selection. Although SSR loci are usually considered just as evolutionarily neutral as DNA markers (Schlötterer and Wiehe, 1999; Schlötterer, 2000), SSR loci of expressed sequence tag-derived SSR markers) have been developed and used for genetic analysis and exploration of the genetic resources of sugarcane (Oliveira et al., 2009). High (EstB60 and EstB130 loci), intermediate (EstB41), and low (EstB145 locus) values of genetic diversity $\left(H_{\mathrm{O}}\right)$ were detected in the 9 sugarcane varieties analyzed in our study (Table 2). Thus, heterozygous phenotypes at the EstB60 and EstB130 loci, as well as at the Smc226CG, Smc1237FL, Smc1047HA, Smc2017FL, and $m S \operatorname{sir} 56$ loci $\left(H_{\mathrm{O}} \geq 0.89\right)$ and favorable alleles at the Smc16SA, Smc1047HA, and mSscir56 loci $\left(G_{\mathrm{ST}}=1.00\right)$, may be targets of artificial selection during the formation of populations, indicating agronomic characteristics that are favorable for sugarcane. The functional significance of a substantial number of SSR loci has been proven by rigorous experiments examining various biological phenomena (Li et al., 2002). Other studies (Subirana and Messeguer, 2008) have indicated that microsatellites with different repeated motifs may be structurally related and involved in the determination of chromosome structure.

Despite the known functional significance of the apparent strong selection detected in some SSR loci, the analysis of genetic structure of the 9 sugarcane varieties using SSR markers was especially important to identify SSR loci with high levels of heterozygosity (EstB60, EstB130, Smc226CG, Smc1237FL, Smc1047HA, Smc2017FL, and mSsir56) and varieties showing high heterozygosity (RB72454, RB92579, RB867515, RB935744, RB855453, $\mathrm{RB} 036152$ ), which can then be used as parents to generate or produce new cultivars.

The plants of the RB72454 and RB92579 sugarcane varieties may also be crossed with varieties that present important agronomic characteristics to broaden the genetic basis in sugarcane. Our study with a small number of varieties contradicts previous indications that the germplasm of sugarcane has a narrow genetic base. A broad genetic basis was observed when 8-10 individual plants of each variety were analyzed. The described primers may be used to check the development of each variety, which should be used for the future generation of new hybrid cultivars. The monomorphic primers UGSM148 and UGSM59 are important markers for monitoring the genetic stability of the Ugsm 148 and Ugsm 59 loci. The UGSM148 and UGSM59 primers may be used as molecular markers to compare the genotype stability in the experimental phase of the breeding program while the genotype is evaluated under various environmental conditions. The monomorphic primers may also be used to evaluate the genetic stability of sugarcane during cycles of vegetative multiplication, i.e., propagation via rhizomes.

\section{ACKNOWLEDGMENTS}

Research supported by Conselho Nacional de Pesquisa Ciência e Tecnologia (Brasí- 
lia, DF), Fundação Araucária (Curitiba, PR), and Coordenação de Aperfeiçoamento de Pessoal de Nível Superior (Brasília, DF, Brasil). We would also like to thank Fazenda Junqueira (Alto Alegre, Colorado, PR, Brasil) for the samples provided.

\section{REFERENCES}

Allendorf FW and Luikart G (2007). Conservation and the Genetics of Populations. Blackwell Publishing, Maden.

Almeida CMCV, Dias LAS, Okabe ET and Medeiros JRP (2005). Variability in genetic resources of cacao in Rondônia, Brazil. Crop Breed. Appl. Biotechnol. 5: 318-324.

Barbosa GVS, Souza AJR, Rocha AMC and Ribeiro CAG (2000). Novas Variedades RB de Cana-de-Açúcar para Alagoas. In: Programa de Melhoramento Genético de Cana-de-Açúcar UFAL, Maceió.

Cordeiro GM and Henry RJ (2001). Sugarcane Microsatellites; Their use and Characteristics. The Plant and Animal Genome IX Conference, San Diego.

Cordeiro GM, Taylor GO and Henry RJ (2000). Characterisation of microsatellite markers from sugarcane (Saccharum sp.), a highly polyploid species. Plant Sci. 155: 161-168.

Cordeiro GM, Casu R, McIntyre CL, Manners JM, et al. (2001). Microsatellite markers from sugarcane (Saccharum spp.) ESTs cross transferable to erianthus and sorghum. Plant Sci. 160: 1115-1123.

D'Hont A, Grivet L, Feldmann P, Rao S, et al. (1996). Characterisation of the double genome structure of modern sugarcane cultivars (Saccharum spp.) by molecular cytogenetics. Mol. Gen. Genet. 250: 405-413.

Don RH, Cox PT, Wainwright BJ, Baker K, et al. (1991). 'Touchdown' PCR to circumvent spurious priming during gene amplification. Nucleic Acids Res. 19: 4008.

Duarte-Filho LSC, Silva PP, Santos JM and Barbosa GVS (2010). Genetic similarity among genotypes of sugarcane estimated by SSR and coefficient of parentage. Sugar Tech. 12: 145-149.

Grivet L and Arruda P (2002). Sugarcane genomics: depicting the complex genome of an important tropical crop. Curr. Opin. Plant Biol. 5: 122-127.

Hernández-Salas JM, Villa-Ramírez MS, Veloz-Rendón JS, Rivera-Hernández KN, et al. (2009). Comparative hydrolysis and fermentation of sugarcane and agave bagasse. Bioresour. Technol. 100: 1238-1245.

Hoisington DM, Khairallah D and Gonzalez-de-Leon L (1994). Laboratory Protocols: CIMMYT Applied Molecular Genetics Laboratory. 2nd edn. CIMMYT.

Lee TSG and Bressan EA (2006). The potential of ethanol production from sugarcane in Brazil. Sugar Tech. 8: 195-198.

Li YC, Korol AB, Fahima T, Beiles A, et al. (2002). Microsatellites: genomic distribution, putative functions and mutational mechanisms: a review. Mol. Ecol. 11: 2453-2465.

Liu P, Que Y and Pan YB (2011). Highly polymorphic microsatellite DNA markers for sugarcane germplasm evaluation and variety identity testing. Sugar Tech. 13: 129-136.

Martín C, Galbe M, Wahlbom C and Hahn-Hägerdal B (2002). Ethanol production from enzymatic hydrolysates of sugarcane bagasse using recombinant xylose-utilising Saccharomyces cerevisiae. Enzyme Microb. Tech. 31: 274282.

Nei M (1973). Analysis of gene diversity in subdivided populations. Proc. Natl. Acad. Sci. U. S. A. 70: 3321-3323.

Neureiter M, Danner H, Thomasser C, Saidi B, et al. (2002). Dilute-acid hydrolysis of sugarcane bagasse at varying conditions. Appl. Biochem. Biotechnol. 98-100: 49-58.

Oliveira KM, Pinto LR, Marconi TG, Mollinari M, et al. (2009). Characterization of new polymorphic functional markers for sugarcane. Genome 52: 191-209.

Pan YB, Cordeiro GM, Richard EP and Henry RJ (2003). Molecular genotyping of sugarcane clones with microsatellite DNA markers. Maydica 48: 319-329.

Pinto LR, Oliveira KM, Ulian EC, Garcia AA, et al. (2004). Survey in the sugarcane expressed sequence tag database (SUCEST) for simple sequence repeats. Genome 47: 795-804.

Rohlf FJ (2000). NTSYS-pc: Numerical Taxonomy and Multivariate Analysis System. Version 2.1. Exeter Software. Setauket.

Ruzene DS, Silva DP, Vicente AA, Teixeira JA, et al. (2009). Cellulosic films obtained from the treatment of sugarcane bagasse fibers with N-methylmorpholine-N-oxide (NMMO). Appl. Biochem. Biotechnol. 154: 38-47.

Schlötterer C (2000). Evolutionary dynamics of microsatellite DNA. Chromosoma 109: 365-371.

Schlötterer C and Wiehe T (1999). Microsatellites, a Neutral Marker to Infer Selective Sweeps. In: Microsatellites: Evolution and Applications (Goldstein DB and Schlötterer C, eds.). Oxford University Press, Oxford, 238-247.

Silva CM, Mangolin CA, Mott AS and Machado MFPS (2008). Genetic diversity associated with in vitro and conventional 
bud propagation of Saccharum varieties using RAPD analysis. Plant Breed. 127: 160-165.

Silva DC, Duarte-Filho LSC, Santos JM and Barbosa GVS (2012). DNA fingerprinting based on simple sequence repeat (SSR) markers in sugarcane clones from the breeding program RIDESA. Afr. J. Biotechnol. 11: 4722-4728.

Singh RK, Srivastava S, Singh SP, Sharma ML, et al. (2008). Identification of new microsatellite DNA markers for sugar and related traits in sugarcane. Sugar Tech. 10: 327-333.

Singh RK, Singh RB, Singh SP and Sharma ML (2011). Identification of sugarcane microsatellites associated to sugar content in sugarcane and transferability to other cereal genomes. Euphytica 182: 335-354.

Sousa LRL (2009). Viabilidade do Uso de Cinzas de Bagaço de Cana-de-Açúcar (CBC) Residuais do Estado de Goiás como Adição Mineral ao Cimento Portland. Master's thesis, Universidade Federal de Goiás, Goiânia.

Subirana JA and Messeguer X (2008). Structural families of genomic microsatellites. Gene 408: 124-132.

Wei X, Jackson PA, McIntyre CL, Aitken KS, et al. (2006). Associations between DNA markers and resistance to diseases in sugarcane and effects of population substructure. Theor. Appl. Genet. 114: 155-164.

Wright S (1951). The genetical structure of populations. Ann. Eugen. 15: 323-354.

Yeh FC, Yang R and Boyle T (1999). Popgene Version 1.32: Microsoft Window-Based Freeware for Population Genetic Analysis. University of Alberta, Center for International Forestry Research, Edmonton.

Zanin GM, Santana CC, Bon EP, Giordano RC, et al. (2000). Brazilian bioethanol program. Appl. Biochem. Biotechnol. 84-86: $1147-116$ 